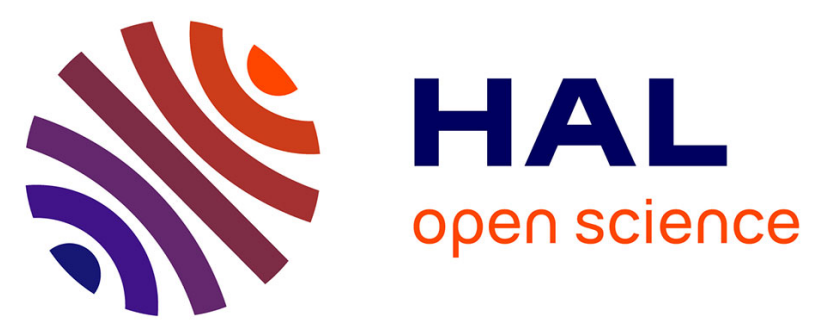

\title{
A new method for the determination of the nitrogen content of nitrocellulose based on the molar ratio of nitrite-to-nitrate ions released after alkaline hydrolysis
}

Elodie Alinat, Nathalie Delaunay, Xavier Archer, Jean-Maurice Mallet, Pierre Gareil

\section{To cite this version:}

Elodie Alinat, Nathalie Delaunay, Xavier Archer, Jean-Maurice Mallet, Pierre Gareil. A new method for the determination of the nitrogen content of nitrocellulose based on the molar ratio of nitrite-tonitrate ions released after alkaline hydrolysis. Journal of Hazardous Materials, 2015, 286, pp.92-99. 10.1016/j.jhazmat.2014.12.032 . hal-01110232

\section{HAL Id: hal-01110232 https://hal.sorbonne-universite.fr/hal-01110232}

Submitted on 27 Jan 2015

HAL is a multi-disciplinary open access archive for the deposit and dissemination of scientific research documents, whether they are published or not. The documents may come from teaching and research institutions in France or abroad, or from public or private research centers.
L'archive ouverte pluridisciplinaire HAL, est destinée au dépôt et à la diffusion de documents scientifiques de niveau recherche, publiés ou non, émanant des établissements d'enseignement et de recherche français ou étrangers, des laboratoires publics ou privés. 
A new method for the determination of the nitrogen content of nitrocellulose based on the molar ratio of nitrite-to-nitrate ions released after alkaline hydrolysis

Elodie Alinat ${ }^{a, b, c, e 1}$, Nathalie Delaunay ${ }^{a, c, e 1}$, Xavier Archer $^{b}$, Jean-Maurice Mallet ${ }^{\mathrm{d}, \mathrm{e}, \mathrm{f}}$, Pierre Gareil $^{\mathrm{a}, \mathrm{c}, \mathrm{e}^{*} 1}$

${ }^{a}$ PSL Research University, Chimie ParisTech, Laboratory of Physicochemistry of Electrolytes, Colloids and Analytical Sciences (PECSA), 11 rue Pierre et Marie Curie, 75005 Paris, France.

${ }^{\mathrm{b}}$ Central Laboratory of Police Prefecture (LCPP), 39bis rue de Dantzig, 75015 Paris, France. ${ }^{\mathrm{C} C N R S}$, UMR 7195 PECSA, 11 rue Pierre et Marie Curie, 75005 Paris, France ${ }^{\mathrm{d}}$ École Normale Supérieure-PSL Research University, Département de Chimie, 24, rue Lhomond, 75005 Paris, France.

${ }^{\text {e}}$ Sorbonne Universités, UPMC Univ Paris 06, LBM, 4 place Jussieu, F-75005, Paris, France.

${ }^{\mathrm{f}} \mathrm{CNRS}$, UMR 7203 LBM, F-75005, Paris, France

E-mail addresses:

elodie.alinat@chimie-paristech.fr

nathalie.delaunay@espci.fr

xavier.archer@interieur.gouv.fr

jean-maurice.mallet@es.fr

pierre.gareil@chimie-paristech.fr

* Corresponding author: Pierre Gareil. Present address : LSABM, UMR 8231 CBI, CNRS-ESPCI ParisTech, 10 rue Vauquelin, 75231 Paris cedex 05, France. Phone: (+33) 14079 4651. Fax: (+33) 14079 4776. E-mail: pierre.gareil@chimie-paristech.fr

\footnotetext{
${ }^{1}$ Present address : LSABM, UMR 8231 CBI, CNRS-ESPCI ParisTech, 10 rue Vauquelin, 75231 Paris cedex 05, France. Phone: (+33) 14079 4651. Fax: (+33) 140794776.
} 


\section{Abstract}

A new method was proposed to determine the nitrogen content of nitrocelluloses (NCs). It is based on the finding of a linear relationship between the nitrogen content and the molar ratio of nitrite-to-nitrate ions released after alkaline hydrolysis. Capillary electrophoresis was used to monitor the concentration of nitrite and nitrate ions. The influences of hydrolysis time and molar mass of NC on the molar ratio of nitrite-to-nitrate ions were investigated, and new insights into the understanding of the alkaline denitration mechanism of NCs, underlying this analytical strategy is provided. The method was then tested successfully with various explosive and non-explosive NC-containing samples such as various daily products and smokeless gunpowders. Inherently to its principle exploiting a concentration ratio, this method shows very good repeatability in the determination of nitrogen content in real samples with relative standard deviation $(n=3)$ inferior to $1.5 \%$, and also provides very significant advantages with respect to sample extraction, analysis time $(1 \mathrm{~h}$ for alkaline hydrolysis, $3 \mathrm{~min}$ for electrophoretic separation), which was about 5 times shorter than for the classical Devarda's method, currently used in industry, and safety conditions (no need for preliminary drying NC samples, mild hydrolysis conditions with $1 \mathrm{M}$ sodium hydroxide for $1 \mathrm{~h}$ at $\left.60^{\circ} \mathrm{C}\right)$.

Keywords: nitrocellulose, nitrogen content, alkaline hydrolysis, smokeless gunpowder

\section{Non-standard abbreviations:}

NC: nitrocellulose

DS: degree of substitution

HDMB: hexadimethrine bromide

BGE: background electrolyte

DPA: diphenyl amine

DNT: dinitrotoluene 


\section{Introduction}

Cellulose nitrate, also more commonly called nitrocellulose (NC), is prepared by nitration of cellulose in nitric and sulfuric acid mixtures [1]. Cellulose is a natural linear polysaccharide composed of glucose units linked by $\beta(1 \rightarrow 4)$ glucosidic bonds. In each of the repeating glucose units, three reactive hydroxyl groups (one primary hydroxyl group on the C6 position and two secondary hydroxyl groups on the $\mathrm{C} 2$ and $\mathrm{C} 3$ positions) are able to undergo esterification reaction, which results in the replacement of the hydroxyl groups by nitro groups in an acidic medium. The degree of substitution (DS), defined as the average number of hydroxyl groups exchanged by nitrate groups per glucose unit, depends on the synthesis conditions. In current applications, it is most often expressed as the nitrogen content. Theoretically, the highest achievable nitrogen content is close to $14.15 \%$ corresponding to fully nitrated NC, having a DS of 3. In practice, however, the maximum attainable nitrogen content is $13.8 \%$ [2]. Indeed, the synthesis of fully nitrated NC is expensive and dangerous, generating unstable compounds such as sulfuric cellulose esters [1]. The nitrogen content is one of the most important parameter determining NC applications, since it strongly affects its physical and chemical properties [2]. NC solubility decreases when the nitrogen content and the degree of polymerization (DP) increase. NCs having nitrogen content below $12.5 \%$ (DS close to 2) are widely used as raw material in daily products (lacquers, varnishes, paints, nail polish, ping pong ball, filter membranes, printing inks, and more recently liquid bandage). Highly-nitrated NCs having a nitrogen content higher than $12.5 \%$ are employed in the manufacturing of energetic materials such as propellants and dynamites.

NC-based smokeless gunpowders are classified according to the number of energetic materials in their composition [3, 4]: i) single-base propellants, which mainly contain NC, ii) double-base propellants consisting of NC and nitroglycerin, and iii) triple-base propellants containing NC, nitroglycerin, and nitroguanidine. Most smokeless gunpowders are formulated with graphite and various other chemicals (such as dinitrotoluene) to monitor burning, reduce muzzle flash, and make them more water resistant. Due to NC deterioration over time (release of nitric acid), smokeless gunpowders also contain small amounts of stabilizers (diphenylamine, diphenyl ureas such as ethyl or methyl centralite) to neutralize acidic byproducts. 
NC characterization remains challenging due to its high molar mass, complex structure, lack of solubility in common organic solvents, both molar mass and functional dispersity, and consideration of safety constraints. Acido-basic titration (Devarda's method) [5], vibrational spectroscopy [6, 7], mass spectrometry [8-10], gas chromatography [11-13], reversed phase $[14,15]$, ion [16-19], and size exclusion [20, 21] chromatography, and capillary electrophoresis [22-24] have been used to characterize NC. Before implementing most of them, long and tedious sample treatment, especially involving alkaline denitration in the absence [18] or in the presence of hydrogen peroxide [5], are needed. For most of them, dangerous NC drying before precise weighing is required. In addition to this, when NC is present in a formulated sample, it should be first extracted to remove potential interfering components or simply to isolate it before weighing. To this aim, a new protocol involving a multistep solvent extraction has just been developed by López-López et al. to isolate NC from smokeless gunpowders [3]. In spite of the existence of all these methods, few of them are relevant for the determination of the nitrogen content of NCs employed in smokeless gunpowders, and there is still a strong demand from analysts to reduce overall analysis time, simplify sample treatment, and improve safety of the assay.

Following our previous work on the optimization by experimental design of alkaline denitration reaction for maximum denitration yield [25], the molar ratio of nitrite-to-nitrate ions released during this reaction was investigated in depth. CE was used to monitor the released nitrite and nitrate ions by a previously developed method [24]. This study was conducted using nine NC standards of known nitrogen content (from 11.14\% to $13.42 \%$ ) and molar mass (from 20000 to $312000 \mathrm{~g} \mathrm{~mol}^{-1}$ ). The influence of reaction time was considered and data were analyzed to gain a deeper insight into the understanding of the alkaline denitration mechanism. This work opens a new route to discriminate NCs according to their nitrogen contents, based on the molar ratio of nitrite-to-nitrate ions found in the posthydrolysis solution. This strategy was successfully applied to as various NC-containing samples as ping pong ball, nail polish, NC membrane, liquid bandage, and smokeless gunpowder to determine their nitrogen content and demonstrate its suitability for real sample analysis, minimizing extraction steps and rendering NC drying useless, thus improving safety conditions.

\section{Experimental section}




\subsection{Standards, real samples, and electrolytes}

NC standards (Table 1$)$ with a nitrogen content of $11.20\left(\mathrm{M}_{\mathrm{w}}=35000 \mathrm{~g} \mathrm{~mol}^{-1}\right.$ and $\mathrm{M}_{\mathrm{w}}=137$ $\left.000 \mathrm{~g} \mathrm{~mol}^{-1}\right), 12.00\left(\mathrm{M}_{\mathrm{w}}=312000 \mathrm{~g} \mathrm{~mol}^{-1}\right)$, and $12.20\left(\mathrm{M}_{\mathrm{w}}=29000 \mathrm{~g} \mathrm{~mol}^{-1}\right)$ were supplied by Dow Chemical Company (Dow Wolff Cellulosics, Bomlitz, Germany). NC samples with a nitrogen content of $11.14\left(\mathrm{M}_{\mathrm{w}}=20000 \mathrm{~g} \mathrm{~mol}^{-1}\right), 12.09\left(\mathrm{M}_{\mathrm{w}}=95000 \mathrm{~g} \mathrm{~mol}^{-1}\right), 12.55\left(\mathrm{M}_{\mathrm{w}}=\right.$ $\left.200000 \mathrm{~g} \mathrm{~mol}^{-1}\right)$, and $13.42\left(\mathrm{M}_{\mathrm{w}}=69000 \mathrm{~g} \mathrm{~mol}^{-1}\right.$ and $\left.\mathrm{M}_{\mathrm{w}}=110000 \mathrm{~g} \mathrm{~mol}^{-1}\right)$ were given by the Central Laboratory of Police Prefecture (LCPP, Paris, France). NCs were stored with a damping agent (water or ethanol) content of approximately $30 \%$. Additional NC standards with nitrogen contents of 11.7 and $12.9 \%$, which were not commercially available to us, were prepared by precisely mixing the appropriate amounts of NC2 with NC6 in 50:50 (w/w) proportions, and NC6 with NC8 in 43:57 (w/w) proportions, respectively, Samples of singlebase smokeless gunpowders with and without graphite (mixtures of NC, diphenylamine (DPA), dibutylphtalate, dinitrotoluene (DNT), potassium sulphate, and calcium carbonate) were provided by LCPP. Ping pong balls, nail polish, and liquid bandage were purchased from a local store. Amersham Biosciences NC membranes (Hybond-C-Extra) were supplied by Dominique Dutscher (Brumath, France).

Sodium nitrite (>97\%), sodium nitrate (>99\%), hexadimethrine bromide (HDMB) used as a coating agent, and sodium molybdate dihydrate $(\geq 99.5 \%)$ used as internal reference were purchased from Sigma-Aldrich (Saint-Quentin-Fallavier, France). Concentrated volumetric solutions (ConvoL Normadose ${ }^{\circledR}$ ) of $1 \mathrm{M}$ sodium hydroxide used as base for NC hydrolysis were obtained from VWR (Fontenay-sous-Bois, France). Detailed protocols for the preparation of background electrolyte (BGE) and standard solutions were given in [24].

\subsection{Instrumentation}

Separations were carried out with a Beckman Coulter $^{\circledR}$ P/ACE MDQ capillary electrophoresis system (Beckman Coulter, Villepinte, France) equipped with a diode array detector. Data processing and acquisition were performed using 32 Karat $^{\circledR} 8.0$ software (Beckman Coulter).

All NC standards were dried with an oven (model UNB100) from Memmert (Schwaback, Germany) to remove damping agent. Alkaline denitration experiments were performed with 
a block heater (model SBH 130D) from Stuart (Staffordshire, UK) capable of receiving twelve 10-mL glass tubes.

\subsection{Electrophoretic conditions}

Nitrite and nitrate ions were determined by a CE method previously developed by our group for this aim [24]. Briefly, separations were performed using Polymicro Technologies bare fused-silica capillaries supplied by Photonlines (Marly-Le-Roi, France) with dimensions of $60 \mathrm{~cm}(50 \mathrm{~cm}$ to the detector $) \times 50 \mu \mathrm{m}$ i.d $\times 365 \mu \mathrm{m}$ o.d.. Before first use, capillaries were conditioned by flushing with $1 \mathrm{M} \mathrm{NaOH}$ followed by $0.1 \mathrm{M} \mathrm{NaOH}$, ultra-pure water, HDMB solution at $1 \mathrm{~g} \mathrm{~L}^{-1}$, and finally BGE, each under $14.5 \mathrm{psi}$ ( 1 bar) for $10 \mathrm{~min}$ (15 capillary volumes). The BGE was $100 \mathrm{mM}$ ionic strength sodium phosphate buffer at $\mathrm{pH}$ 7.7. Before each run, the capillary was rinsed with HDMB solution under 14.5 psi for 1 min (about 1.5 capillary volume) and BGE under 14.5 psi for 2 min (about 3 capillary volumes). Injections were performed hydrodynamically under $0.5 \mathrm{psi}$ for $3 \mathrm{~s}(0.3 \%$ of capillary volume). Separations were conducted under $-30 \mathrm{kV}$ (reversed polarity). Capillary cartridge temperature was maintained at $25^{\circ} \mathrm{C}$. The detection wavelength was set at $210 \mathrm{~nm}$ with a reference at $310 \mathrm{~nm}$ and with bandwidths set at $\pm 10 \mathrm{~nm}$ and $\pm 40 \mathrm{~nm}$, respectively. After the last analysis of the day, capillary was rinsed with water under 14.5 psi for 10 min (15 capillary volumes) and stored in the apparatus both ends in water. The figures of merit for this method (least-squares regression parameters, regression coefficient, linearity, range, LOD, LOQ) were given in [24].

\subsection{Alkaline hydrolysis of NC standards}

Prior to hydrolysis, about $40 \mathrm{mg}$ of wet NC were placed in weighed $10-\mathrm{mL}$ glass tubes and dried in an oven at $100^{\circ} \mathrm{C}$ for $2 \mathrm{~h}$ to ensure constant weight. Then, to reach room temperature, tubes containing dry NC were placed for $25 \mathrm{~min}$ in a glass desiccator. After the drying step, the glass tubes containing dry NC were weighed again in order to obtain the exact amount of $\mathrm{NC}$ subjected to alkaline hydrolysis. Next, $5 \mathrm{~mL}$ of $1 \mathrm{M}$ sodium hydroxide solution were introduced into each tube containing dry NC and the tubes were screwcapped. The stopped tubes were placed in the block heater and heated at $60^{\circ} \mathrm{C}$ for the determined reaction time within the studied range $(5 \min -1 \mathrm{~h})$. The denitration reaction was stopped by transferring the tubes into an ice bath for $15 \mathrm{~min}$ to lower the temperature 
very quickly. After $25 \mathrm{~min}$ at room temperature, a defined volume of hydrolysate was transferred into water containing the appropriate amount of the internal standard (molybdate) solution at $1 \mathrm{~g} \mathrm{~L}^{-1}$. The dilution factor (between 2 and 20) was adapted according to sample. Prior to electrophoresis analysis, all samples were filtered through a $0.20 \mu \mathrm{m}$ cellulose acetate membrane. This protocol was repeated for each studied reaction time and NC standard samples. Finally, nitrite and nitrate ion concentrations in hydrolysates were determined by CE analysis.

\subsection{Real samples}

To isolate NC from a single-base smokeless gunpowder, about $0.2 \mathrm{~g}$ of smokeless gunpowder was subjected to a multistep solvent extraction procedure (comprising three extractions with methanol and two extractions with water) that was adapted from [3] by suppressing the final extraction with methyl ethyl cetone and therefore the tedious evaporation of this last solvent. This modified procedure was already outlined in Figure 1 of ref. [24]. Most of solid NC was recovered after the second extraction by water and introduced into three 10$\mathrm{mL}$ glass tubes to which each $5 \mathrm{~mL}$ of $1 \mathrm{M}$ sodium hydroxide solution were added. The stopped tubes were then placed in the block heater and heated at $60^{\circ} \mathrm{C}$ for $1 \mathrm{~h}$. When the reaction time ended, the reaction was stopped and the tubes were allowed to return to room temperature as explained in $\S 2.4 .250 \mu \mathrm{L}$ of the hydrolysates were introduced into a $10 \mathrm{~mL}$ volumetric flask containing $200 \mu \mathrm{L}$ of the internal standard solution at $1 \mathrm{~g} \mathrm{~L}^{-1}$ and supplemented to the mark with ultra-pure water.

About $60 \mathrm{mg}$ of ping pong ball or NC membrane were introduced into 10-mL glass tubes and dissolved in $3 \mathrm{~mL}$ acetone under stirring. The mixture was placed in an oven at $60^{\circ} \mathrm{C}$ until complete solvent evaporation. Then, $5 \mathrm{~mL}$ of $1 \mathrm{M}$ sodium hydroxide solution were introduced into the glass tubes containing the residue obtained by removing the organic solvent. The stopped tubes were placed in the block heater and heated at $60^{\circ} \mathrm{C}$ for $1 \mathrm{~h}$. The end of the protocol was identical to that described above for NC in smokeless gunpowder.

For the hydrolysis of nail polish and liquid bandage, approximately $0.3 \mathrm{~g}$ of liquid matter were placed directly in 10-mL glass tubes. Next, $5 \mathrm{~mL}$ of $1 \mathrm{M}$ sodium hydroxide solution were added into the glass tubes. The samples were then hydrolyzed at $60^{\circ} \mathrm{C}$ for $1 \mathrm{~h}$ with $1 \mathrm{M}$ 
sodium hydroxide solution. The rest of the protocol was identical to the one described before for NC in smokeless gunpowder.

\subsection{Quantitation of nitrite and nitrate ions}

Quantitation of nitrite and nitrate ions was performed by the validated CE method from normalized corrected peak areas (i.e. analyte peak areas divided by analyte migration time and by internal standard peak area divided by its migration time) using external standard calibration. From these concentrations, molar ratios of nitrite-to-nitrate ions were directly calculated. Denitration yields were also calculated according to equation (1) in [24].

\subsection{Safety considerations}

NC in dry state is a highly flammable solid that ignites easily and burns explosively when is concealed. This is why it should always be stored wet. NCs having nitrogen content higher than $12.5 \%$ are classified as explosives. NC can be ignited by flame, heat, shock, friction, sparks or static electricity. Its explosive propensity depends on the nitrogen content. The higher the nitrogen content, the easier it can explode. The oven door opening and closing system was modified to prevent confinement in case of explosion. Special attention was paid to keep NC samples wet when stored in a refrigerator and to weigh them after drying in the desiccator to avoid any shock. Security glasses and protection clothes were worn by the operator. In addition, weighing of dry matter was always performed under the assistance of a person equipped with a water vaporizer to prevent from any fire start. For NC standards, working under less than $30 \mathrm{mg}$ dry matter considerably reduces hazard risks. Indeed, it is worthy of note that no incident has occurred over several hundreds of assays that have been realized to date under these experimental conditions.

\section{Results and discussion}

\subsection{Influence of the nitrogen content of NC on the molar ratio of nitrite to nitrate ion} Several works have already shown that the alkaline hydrolysis of NCs mainly results in NC denitration $[18,19,24,26,27]$, with nitrite and nitrate ions being the very main compounds containing nitrogen $[18,24,26,27]$. The release of these anions has been so far explained by competitive reactional mechanisms [28]. Although this mechanism does not allow to specify a value for this ratio, a nitrite to nitrate molar ratio close to 3 has been set forth, regardless 
of the nitrogen content of the NC [26], and of hydrolysis time, suggesting a single step process [27]. Unexpectedly, however, from our preceding work on the optimization of the reaction conditions for maximizing the denitration yield of explosive and non-explosive NCs [25], some correlation appeared to us between NC nitrogen content and the molar ratio of nitrite and nitrate, for all hydrolysis conditions tested in the experimental design. Furthermore, these ratios seem to be almost independent of sodium hydroxide concentration (within the range 1-5 M), temperature (within the range $60-90^{\circ} \mathrm{C}$ ), and reaction time (within the range $1-4 \mathrm{~h}$ ) used for alkaline hydrolysis.

Following this study, the influence of nitrogen content on the molar ratio of nitrite-to-nitrate ions released during the alkaline hydrolysis of the nine NC standards was investigated in depth, for shorter reaction times than studied before $(0-1 \mathrm{~h})$, in $1 \mathrm{M}$ sodium hydroxide at $60^{\circ} \mathrm{C}$. These latter conditions were chosen as they corresponded to those leading to maximum denitration yield for highly-nitrated NCs (except for time) and as they were more user-friendly. Figure 1 shows the obtained variations of molar ratio of nitrite-to-nitrate ions as a function of time for 6 NC standards differing in nitrogen content and/or molar mass. Over the first hour of reaction, a decrease in this ratio occurs likely towards a limiting value, but a clear differentiation of the NCs according to their nitrogen content still remain apparent, especially between the explosive and the non-explosive ones (except for NC7, the behavior of which will be discussed later). Interestingly, some of the curves obtained exhibit parallel evolutions (NC2, NC4, NC7), while some others are crossing (NC8 / NC9 or NC6 / NC7), which could be due to both the closer values of nitrogen contents and the higher standard deviations for the measurements performed for reaction times lower than $30 \mathrm{~min}$. Nevertheless, an improvement in repeatability was not deemed necessary, as the tendency of the curves is apparent enough. Furthermore, the molar mass of the NCs seems to hardly have an impact on the nitrite-to-nitrate molar ratios obtained after a one-hour hydrolysis, as exemplified by standards NC8 and NC9, having the same nitrogen content, but different molar masses (69000 and 110000, respectively). To provide a deeper insight into the observed phenomena, the denitration yields obtained for these six NC standards over the first hour of reaction were represented in Figure 2. Over this time period, denitration yields remained basically inferior to 50\%. For reaction time lower than $20 \mathrm{~min}$ the obtained denitration yields were even less than $20 \%$, leading to concentrations of nitrite and nitrate ions close to the limits of quantitation with the used CE method. These low values help to 
explain the high standard deviations obtained for the molar ratio of nitrite-to-nitrate ions at these times in Figure 1. For these reasons, more attention was paid to data obtained after 1 h-hydrolysis in the following of this study. It is worthy of note that for non-explosive NCs, denitration yields increased in the reversed order of their molar masses, while for explosive NCs, lower denitration yields were obtained on the whole, displaying much less influence of their molar masses. Figure 3 shows the plot of the molar ratio of nitrite-to-nitrate ions versus NC nitrogen content for the nine NC standards after one hour's hydrolysis by $1 \mathrm{M}$ sodium hydroxide at $60^{\circ} \mathrm{C}$. A strong linear correlation exists between the molar ratio of nitrite-to-nitrate ions and the nitrogen content. It is worthy of note that the experimental point for NC7 is below the straight line, suggesting that the obtained nitrogen content for this sample might be lower than that given by the manufacturer (12.55\%), and consequently, might behave as a non-explosive NC. This result is consistent with the observed time variation of molar ratio of nitrite-to-nitrate ions for this sample, which made it closer to the behavior of a non-explosive NC, and also confirmed the abnormal behavior noticed in our earlier work [25]. Therefore, this standard NC was not considered in the remainder of the study. Least-squares linear regression performed on the molar ratio of nitrite-to-nitrate ions obtained for the remaining eight commercial NCs resulted in a regression coefficient equal to 0.95 with a residual standard deviation of 0.23 . As the nitrogen contents of the commercially available NC standards were not evenly distributed over the whole nitrogen content range (11.2 - 13.5\%), two additional NC standards were carefully prepared at 11.7 and $12.9 \%$ by mixing the appropriate amounts of commercial NC standards. As shown in Figure 3, the addition of these new NC standards does not significantly alter either the obtained regression coefficient (equal to 0.94 ) or the residual standard deviation (0.23). The nitrogen content of NC7 was then recalculated using the linear regression obtained from the ten NC standards altogether, and a value of $12.1 \%$ was obtained. This value, lower than $12.5 \%$, corresponds to the one for a non-explosive NC, consistently with the behavior observed in Figure 1 for this NC.

\subsection{Highlight on the alkaline denitration reaction}

The results obtained in this work (see especially Figure 1) demonstrate that the molar ratio of nitrite-to-nitrate ions could be very different from 3, as anticipated from previous 
literature $[26,28]$, and varies in the time course of the denitration reaction. This provides a deeper insight into the understanding of the kinetics of the competing denitration reactions. NC is a statistical assembly of nitrated glucose units linked in $\beta$ (1->4). It is thus composed by the statistical/ random association of non-nitrated glucose unit, mono-nitrated (3 cases), dinitrated units (3 cases, one of them is 2,3-dinitro), and trinitrated units (see Figure 4, insert). Accordingly, nitration ratio is practically expressed as the percentile nitrogen content, which gives an evaluation of the mean value of substitution (in comparison with theoretical percents: mono: 6.8\%; di: 11.1\%; tri: $14.1 \%)$. Clearly, a "dinitrated" (11.1\% nitrogen) NC contains also mono and trinitrated units. In these glucopyranose units, two different environments for nitrate groups, viz isolated nitrates (close to $\mathrm{OH}$ or $\mathrm{OCH}$ ) and vicinal nitrates, can exist.

Our working hypothesis is that the nitrate groups in a vicinal nitrate tandem are hydrolyzed faster and give a higher molar nitrite-to-nitrate ratio (a combined ratio around 6 for the two nitrates). By contrast, the isolated nitrate groups are hydrolyzed slower and give a lower ratio, around 1.5. This hypothesis is consistent with the final nitrite-to-nitrate ratio, linearly dependent on nitrogen content (i.e. vicinal nitrate content). It is also consistent with the kinetics of the observed nitrite-to-nitrate ratio: (i) high and almost constant for trinitrated NC (as all glucopyranose units contained vicinal nitrates), and (ii) decreasing for less nitrated compounds, due to random mixture of glucopyranoses. The trinitrated units are present even in NCs having a nitrogen content of $11 \%$, and they account for the high initial ratio. Once hydrolyzed, the ratio falls to the one corresponding to isolated nitrates. As NCs, especially highly nitrated ones, are insoluble in aqueous $\mathrm{NaOH}$, a delay time of about 5 min is needed for the hydration process, before the denitration starts.

The proposed mechanism of the two pathways ( $a$ and $b$ ) of the alkaline denitration is depicted on Figure 4 for a dinitrate unit. In the first one (a), the hydroxide ion attacks the positive nitrogen, giving back the alcohol and nitrate ion; this reaction is probably not perturbed by carbohydrate modifications far from the nitrogen center. In the second one (b), the hydroxide ion attacks the proton close to the nitrate, leading to a ketone and a nitrite ion: the alcohol is oxidized and the nitrogen reduced. This mechanism is well known for chromate, permanganate oxidation of alcohols, in Swern oxidation [29]. Pathways (b) will be favored (as compared to pathway (a)) by the presence of electro-attracting groups enhancing the acidity of this proton, such as a nitrate or a keto group, so b2 and b3 steps are 
expected to be faster than b1. This mechanism explains the fast and predominant pathway (b) in vicinal nitrated blocks, which is consistent with the high initial nitrite-to-nitrate ratio, and the high initial denitration rate.

\subsection{Applications to real samples}

The correlation between the molar ratio of nitrite-to-nitrate ions and the nitrogen content of NC standards (Figure 3) prompted us to consider this approach for the determination of nitrogen content of NCs used in various real formulated samples, such as a ping pong ball, a NC membrane, a liquid bandage, a nail polish, and smokeless gunpowders with or without graphite. Sample treatments were detailed in $\S 2.5$. Ping pong ball and membrane were merely solubilized and evaporated, prior to be submitted to the alkaline hydrolysis. Liquid samples (nail polish and liquid bandage) can be directly submitted to the alkaline hydrolysis without any pretreatment. Single-base smokeless gunpowders were treated according to a simplified and safer procedure that we experienced in a previous work [24]. Given the approximate NC content in smokeless gunpowders, the initial sample amount to be treated was evaluated so as to realize three alkaline hydrolyses on three independent extractions. This amount, however, could eventually be strongly reduced, insofar as the final sample of nitrite and nitrate ions submitted to CE was diluted forty times in the present protocol. The conditions retained for the alkaline hydrolysis ( $1 \mathrm{M}$ sodium hydroxide at $60^{\circ} \mathrm{C}$ for $1 \mathrm{~h}$ ) were less stringent than those leading to maximum denitration yields for explosive and nonexplosive NCs, as previously determined from a multivariate study of the denitration reaction [25]. The reaction time was fixed at $1 \mathrm{~h}$ as lower RSDs were obtained for the nitriteto nitrate-ratios with standard NCs than those obtained with even shorter times (Figure 1). A typical electrophoregram of an alkaline hydrolysate of NC contained in nail polish is presented in Figure 5, demonstrating there were no interfering peaks within the migration time of nitrite, nitrate, and molybdate ions (internal standard). Finally, nitrogen contents in real samples were determined by interpolating the nitrite-to-nitrate ratio of the real sample in the calibration curve built for NC standards, using the same experimental conditions. The results obtained for the nitrogen contents of the six real samples by using Figure 3 as a calibration curve are given in Table 2. Very good agreements with the data provided by the manufacturers, along with very narrow RSDs for most of them, were shown, demonstrating 
that the method is precise and accurate, in spite of a rather modest regression coefficient for the calibration line. It is worthy of note that this approach does not require (i) to quantitatively extract NC from a formulated sample (ii) to obtain a pure extract (as long as co-extracted compounds do not release nitrite or nitrate ions under alkaline conditions), (iii) to know the exact mass of dried NC involved in the assay, and (iv) to know the yield of the alkaline denitration reaction. At this point it should be emphasized that the protocol for drying NC standards given in $\S 2.4$ is only intended for the experiments aiming at determining denitration yields, which is not required for the final analytical protocol. Furthermore, as only a concentration ratio is used for the nitrogen content determination, a number of experimental error sources were suppressed. These factors are likely at the origin of the high repeatabilities experienced. Finally, as far as safety conditions are concerned, the main advantages of this method over those previously in use $[5,18,20]$ are the absence of need for drying NC-containing samples, the use of mild hydrolysis conditions (especially temperature, $60^{\circ} \mathrm{C}$, and sodium hydroxide concentration, $1 \mathrm{M}$ ), the small size of the assay and the simplified extraction protocols.

\section{Conclusions}

The finding of a linear relation between the nitrogen content of NCs and the molar ratio of nitrite-to-nitrate ions released after alkaline hydrolysis, on one hand, and the kinetic study of the denitration reaction and interpretation of the involved mechanism, on the other hand, prompted us to develop a new analytical methodology for the determination of the nitrogen content of NCs in smokeless gunpowders and various daily products. This method opens great perspectives as it provides significant improvements over those currently in use in industry, such as Devarda's, with respect to sample extraction, analysis time and most importantly safety conditions, while retaining similar high precision and accuracy. 


\section{Acknowledgements}

The authors would like to acknowledge the Laboratoire Central of Prefecture de Police (Paris, France) for funding E. Alinat and X. Archer, and part of this work, Chimie ParisTech (Paris, France) for funding P. Gareil and part of this work, and CNRS (Paris, France) for funding N. Delaunay and J.-M. Mallet and part of this work. 


\section{References}

[1] C.W. Saunders, L.T. Taylor, A review of the synthesis chemistry and analysis of nitrocellulose, J. Energ. Mater. 8 (1990) 149-201.

[2] M. A. Fernández de la Ossa, M. López-López, M. Torre, C. García-Ruiz, Analytical techniques in the study of highly-nitrated nitrocelluloses, Trends Anal. Chem. 30 (2011) $1740-1755$

[3] M. López-López, M. A. Fernandez de la Ossa, J. Saiz-Galindo, J. L. Ferrando, A. Vega, M. Torre, C. García-Ruiz, New protocol for the isolation of nitrocellulose from gunpowders: utility in their identification, Talanta 81 (2010) 1742-1749.

[4] M. López-López, J. Carlos-Bravo, C. García-Ruiz, M. Torre, Diphenylamine and derivatives as predictors of gunpowder age by means of HPLC and statistical models, Talanta 103 (2013) 214-220.

[5] Taux d'azote nitrique des nitrocelluloses (méthode de Devarda), GEMO FN-102-A-1, (1989).

[6] D. S. Moore, S. D. McGrane, Comparative infrared and Raman spectroscopy of energetic polymers, J. Mol. Struct. 661 (2003) 561-566.

[7] D. Dolinak, S. H. Wise, C Jones, Microscopic and spectroscopic features of gunpowders and its documentation in gunshot wounds in charred bodies, Am. J. Forensic Med. Pathol. 29 (2008) 312-319.

[8] K. Hakansson, R. V. Coorey, R. A. Zubarev, V. L. Talrose, P. Hakansson, Low-mass ions observed in plasma desorption mass spectrometry of high explosives, J. Mass Spectrom. 35 (2000) 337-346.

[9] C. M. Mahoney, G. Gillen, A. J. Fahey, Characterization of gunpowder samples using timeof-flight secondary ion mass spectrometry (TOF-SIMS), Forensic Sci. Int. 158 (2006) 39-51.

[10] W. Meier-Augenstein, H. F. Kemp, C. M. Lock, $\mathrm{N}_{2}$ : a potential pitfall for bulk ${ }^{2} \mathrm{H}$ isotope analysis of explosives and other nitrogen-rich compounds by continuous-flow isotope-ratio mass spectrometry, Rapid Commun. Mass Spectrom. 23 (2009) 2011-2016.

[11] D. M. Cropek, P. A. Kemme, J. M. Day, J. Cochran, Development of a novel headspace sorptive extraction method to study the aging of volatile compounds in spent handgun cartridges, Environ. Sci. Technol. 36 (2002) 4346-4351.

[12] K. Katoh, L. Le, M. Kumasaki, Y. Wada, M. Arai, M. Tamura, Study on the spontaneous 
ignition mechanism of nitric esters (I), Thermochimica Acta 431 (2005) 161-167.

[13] K. Katoh, L. Lu, M. Kumasaki, Y. Wada, M. Arai, Study on the spontaneous ignition mechanism of nitric esters (III), Thermochimica Acta 431 (2005) 173-176.

[14] M. Combs, Methodology for determination of nitrogen content in nitrocellulose, US Patent WO2013006218 A1.

[15] P. van Rooijen, Characterization of nitrocellulose by 2D-HPLC, Bachelor thesis, University of Amsterdam, 2013, www.science.uva.nl/onderwijs/.../f1544880797. Last accessed september 15, 2014.

[16] D. Cropek, B. Dankowski, Sonolysis of nitrocellulose fines, US Army Corps of Engineers, Engineer Research and Development Center, Technical report ERDC/CERL TR-00-14 (May 2000).

[17] D. K. MacMillan, C. R. Majerus, R. D. Laubscher, J. P. Shannon, A reproducible method for the determination of nitrocellulose in soil, Talanta 74 (2008) 1026-1031.

[18] M. López-López, J. M. Ramiro-Alegre, C. García-Ruiz, M. Torre, Determination of the nitrogen content of nitrocellulose from smokeless gunpowders and collodions by alkaline hydrolysis and ion chromatography, Anal. Chim. Acta 685 (2011) 196-203.

[19] D. L. Freedman, J. M. Cashwell, B. J. Kim, Biotransformation of explosive-grade nitrocellulose under denitrifying and sulfidogenic conditions, Waste Manage 22 (2002) 283292.

[20] P. Deacon, A. Macdonald, P. Gill, N. Mai, M. A. Bohr, H. Pontius, M. Hust, W. Klerk, C. Bater, A new, internationally accepted standard for testing nitrocellulose, STANAG 4178 (ED2) (2009).

[21] M. Marx-Figini, O. Soubelet, Size exclusion chromatography (GPC) of cellulose nitrate using modified silicagel as stationary phase, Polym. Bull. 6 (1982) 501-508.

[22] M. A. Fernández de la Ossa, M. Torre, M. C. García-Ruiz, Determination of nitrocellulose by capillary electrophoresis with laser-induced fluorescence detection, Anal. Chim. Acta 745 (2012) 149-155.

[23] M. A. Fernández de la Ossa, F Orteja-Ojeda, C. García-Ruiz, Discrimination of nonexplosive and explosive samples through nitrocellulose fingerprints obtained by capillary electrophoresis, J. Chromatogr. A 1302 (2013) 197-204. 
[24] E. Alinat, N. Delaunay, C. Costanza, X. Archer, P. Gareil, Determination of the nitrogen content of nitrocellulose by capillary electrophoresis after alkaline denitration, Talanta 125 (2014) $174-180$

[25] E. Alinat, N. Delaunay, X. Archer, P. Gareil, Multivariate optimization of the denitration reaction for safer determination of nitrocellulose nitrogen content, submitted for publication (2014).

[26] C. Christodoulatos, T. L. Su, A. Koutsospyros, Kinetics of the alkaline hydrolysis of nitrocellulose, Water. Environ. Res. 73 (2001) 185-191.

[27] T. L. Su, C. Christodoulatos, Destruction of nitrocellulose using alkaline hydrolysis, National Technical Information Service, US Department of Commerce, ADP017728 (May 1996).

[28] M. Edge, N. S. Allen, M. Hayes, P. N. K. Riley, C. V. Horie, J. -L. Gardette, Mechanisms of deterioration in cellulose nitrate base archival cinematographic film, European Polymer J. 26 (1990) 623-630

[29] K. Omura, D. Swern, Oxidation of alcohols by "activated" dimethyl sulfoxide. A preparative steric and mechanistic study, Tetrahedron 34 (1978) 1651-1660. 


\section{Figure captions}

Figure 1. Representation of the molar concentration ratio of nitrite-to-nitrate ions as a function of the reaction time for hydrolysis at $60^{\circ} \mathrm{C}$ with $1 \mathrm{M}$ sodium hydroxide. Error bars represent \pm one standard deviation $(n=3)$. Nitrocellulose identification: see Table 1.

Figure 2. Representation of the denitration yields as a function of the reaction time for hydrolysis at $60^{\circ} \mathrm{C}$ with $1 \mathrm{M}$ sodium hydroxide. Error bars represent \pm one standard deviation $(n=3)$. NC identification: see Table 1.

Figure 3. Plot of the molar concentration ratio of nitrite to nitrate ions versus the nitrogen content of nitrocellulose (NC) standards for hydrolysis at $60^{\circ} \mathrm{C}$ for $1 \mathrm{~h}$ with $1 \mathrm{M}$ sodium hydroxide. NC identification: blue diamonds and green triangle: commercial NC standards (see Table 1); orange circle: additional NC standards prepared by mixing of two commercial NC standards. Error bars (sometimes hidden by the symbols) represent \pm one standard deviation $(n=3)$. Dashed line: least-squares regression correlation for all commercial NC standards but NC7 (green triangle) (eight points). Full line: least-squares regression correlation for the eight preceding commercial NC standards + the two additional standards prepared by mixing (orange circles) (ten points).

Figure 4. Denitration mechanisms: A) pathways for vicinal nitrate alkaline "hydrolysis" B) the three environments for a nitrate group and kinetics comparison. Insert: glucose units present in NCs, with vicinal nitrate glucopyranoses represented in blue.

Figure 5. Electropherograms of an alkaline hydrolysate of NC contained in nail polish spiked with $\mathrm{MoO}_{4}{ }^{2-}$ at $20 \mathrm{mg} \mathrm{mL}^{-1}$ and diluted 40 times with water. Hydrolysis conditions: $1 \mathrm{M} \mathrm{NaOH}$ for $1 \mathrm{~h}$ at $60^{\circ} \mathrm{C}$. CE conditions: bare-fused silica capillary, $50 \mu \mathrm{m} \mathrm{ID} \times 60 \mathrm{~cm}$ (detection at 50 $\mathrm{cm}$ ); electroosmotic flow reversal with $1 \mathrm{~g} \mathrm{~L}^{-1} \mathrm{HDMB}$; BGE: $100 \mathrm{mM}$ ionic strength sodium phosphate, $\mathrm{pH} 7.7$; temperature: $25^{\circ} \mathrm{C}$; applied voltage: $-30 \mathrm{kV}$; hydrodynamic injection, 0.5 psi, $3 \mathrm{~s}$; detection: UV at $210 \mathrm{~nm}$. Identification: nitrite (1), nitrate (2), molybdate (3), unidentified $(4,5)$. 


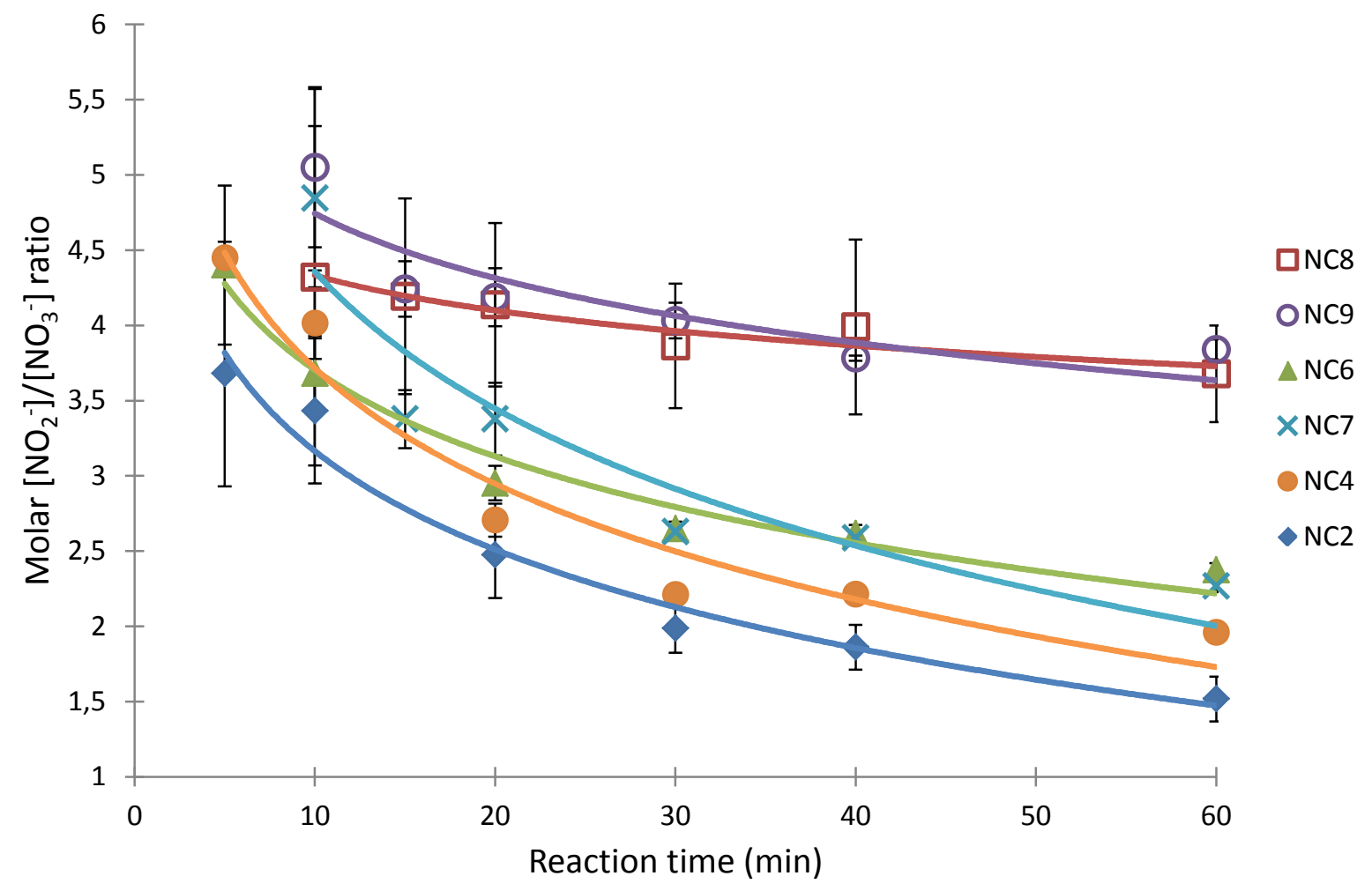

Figure 1 


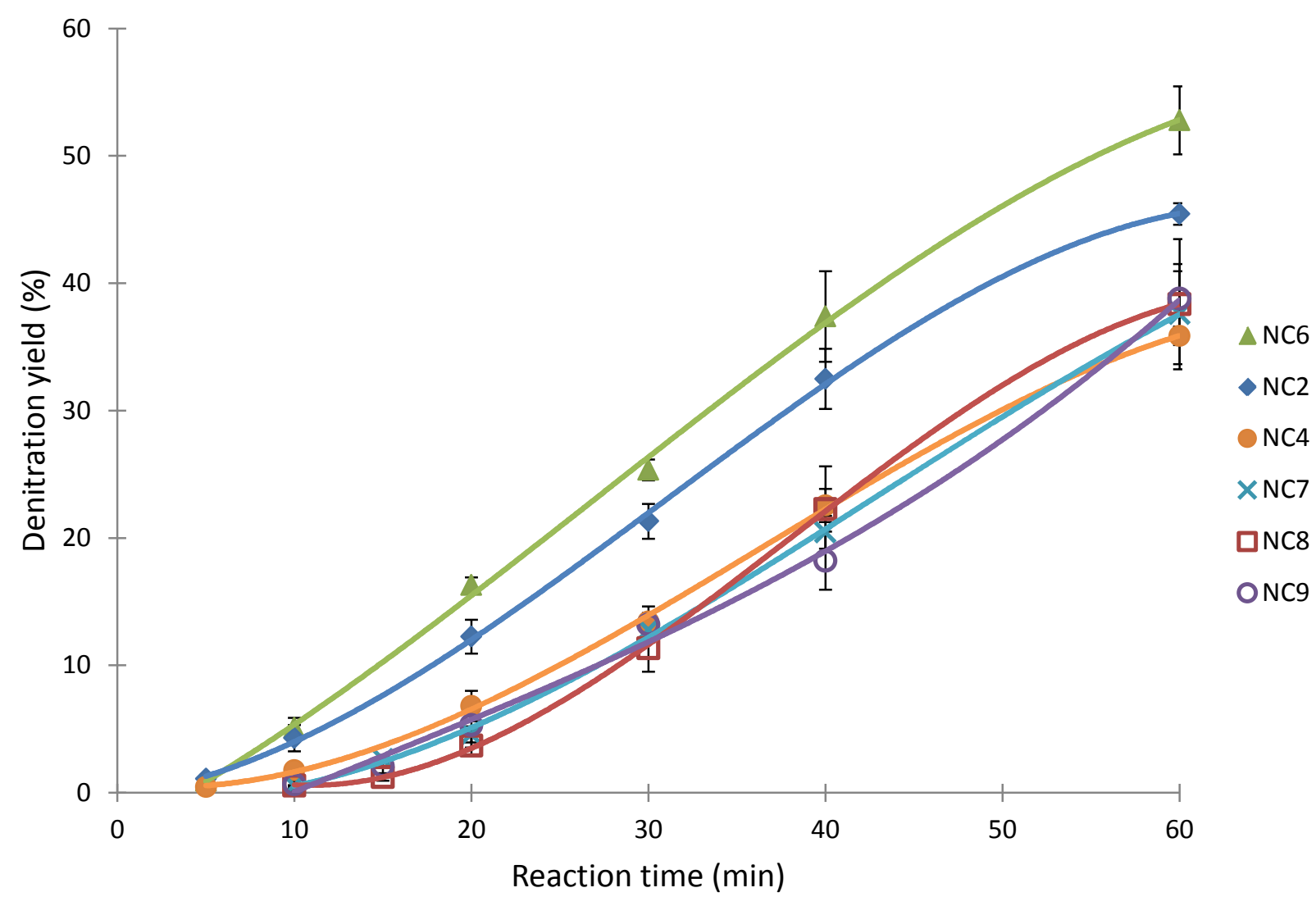

Figure 2 


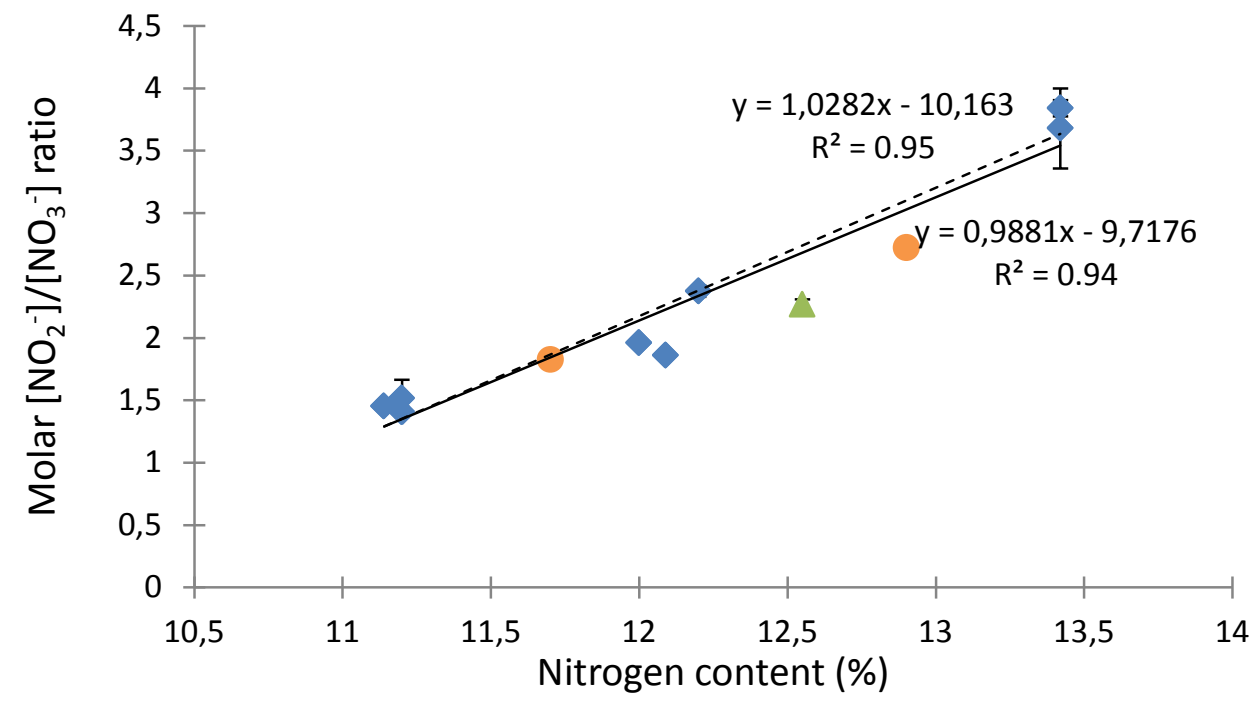

Figure 3 


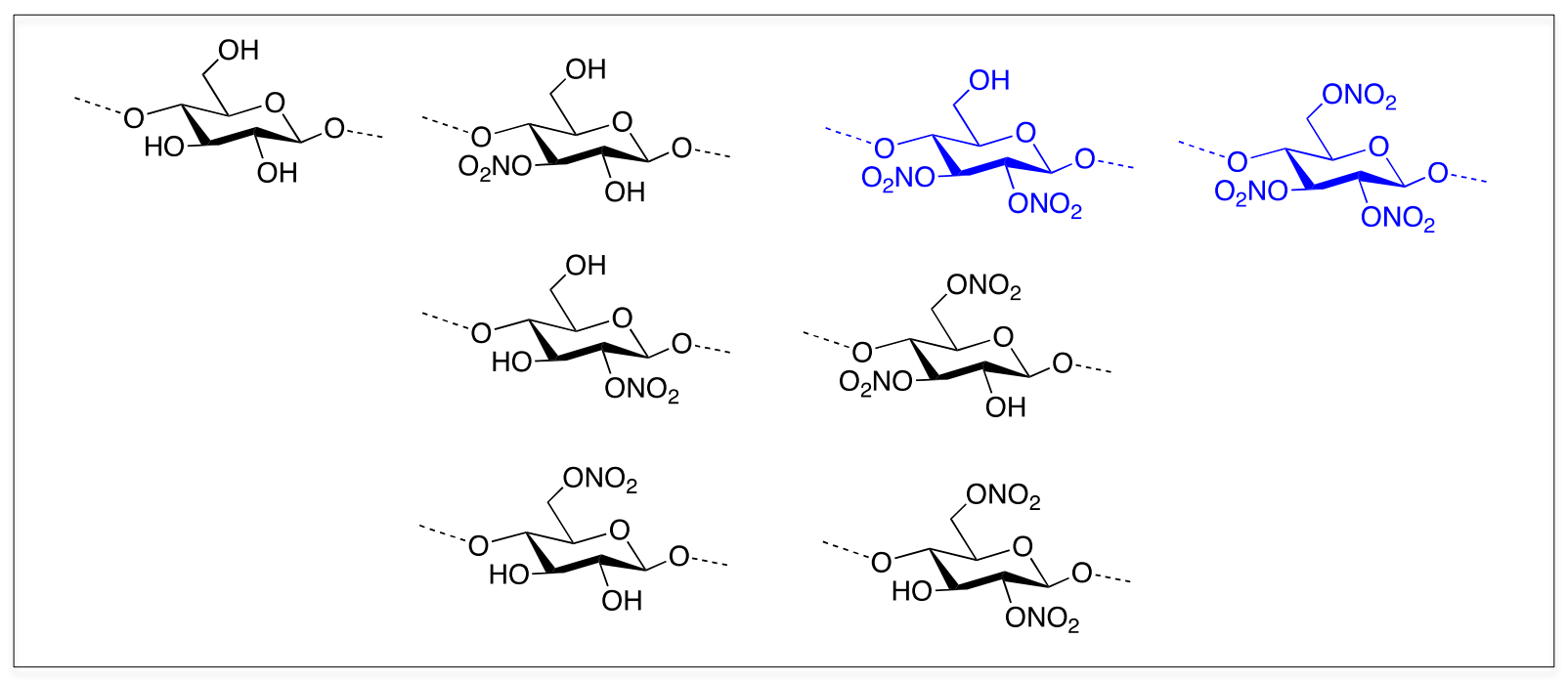

A)

B)
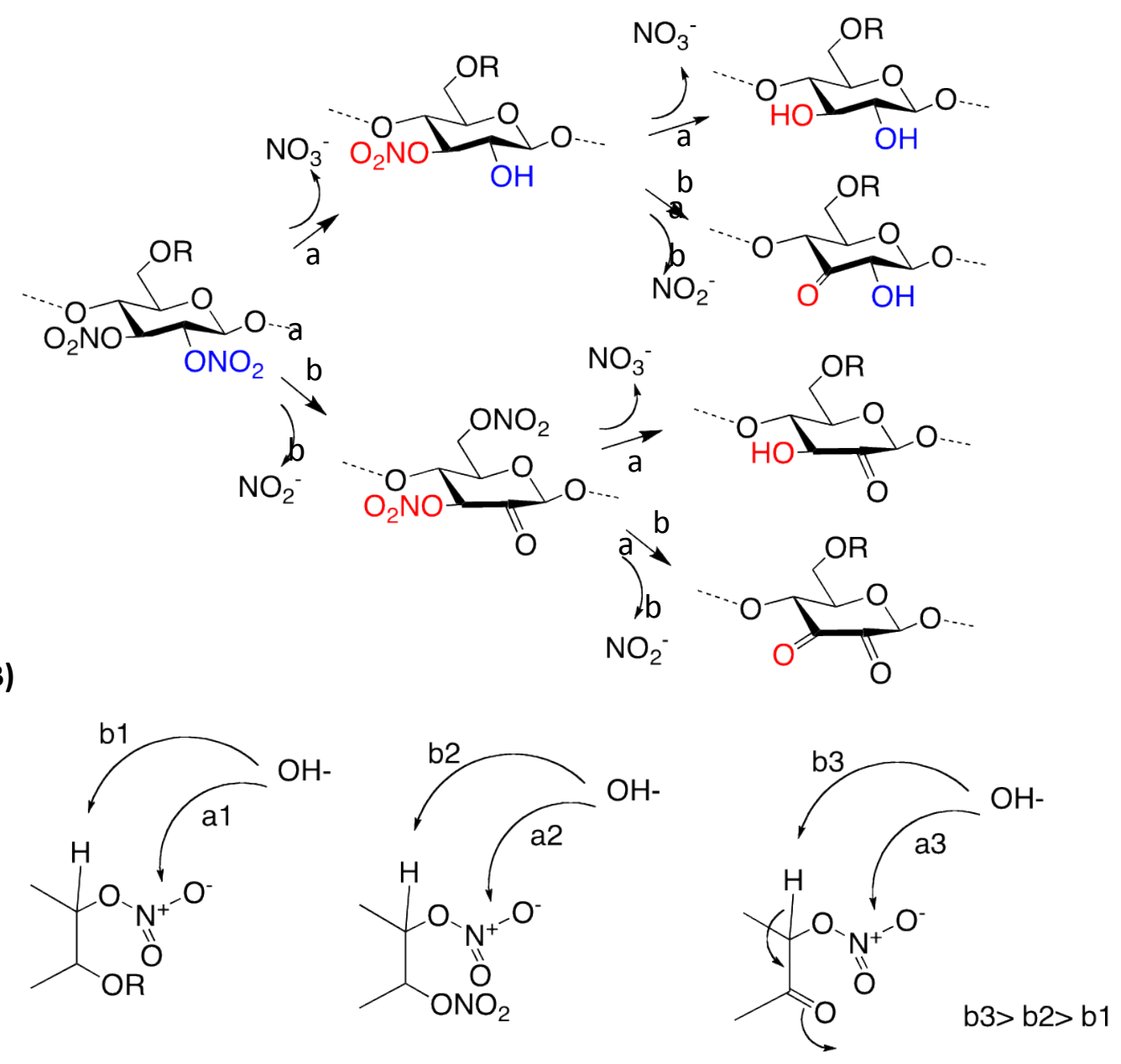

Figure 4 


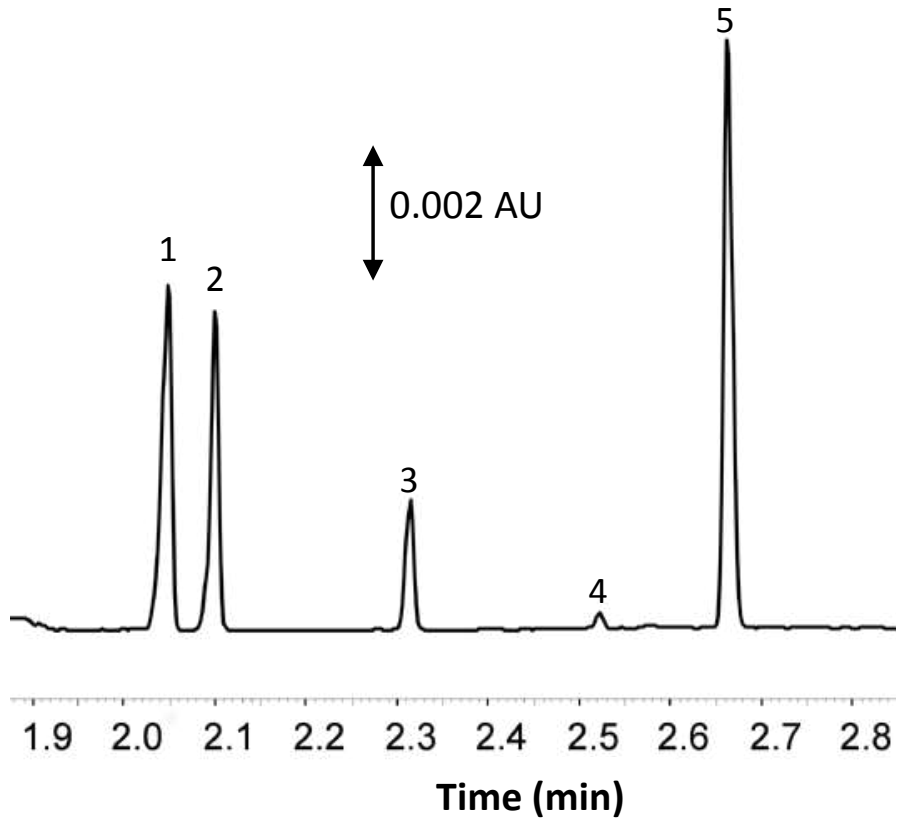

Figure 5 
Table 1: Nitrogen content, substitution degree, and molar mass of the nine studied commercially available NC standards.

\begin{tabular}{cccccc}
\hline $\begin{array}{c}\text { Identification } \\
\text { code }\end{array}$ & $\begin{array}{c}\text { Nitrogen } \\
\text { content (\%) }\end{array}$ & $\begin{array}{c}\text { Substitution } \\
\text { degree }\end{array}$ & $\mathrm{M}_{\mathrm{w}}(\mathrm{g} / \mathrm{mol})$ & $\begin{array}{c}\text { Explosives } \\
\text { properties }\end{array}$ & $\begin{array}{c}\text { Damping } \\
\text { agent }\end{array}$ \\
\hline NC1 & 11.14 & 2.0 & 20000 & no & ethanol \\
NC2 & 11.20 & 2.0 & 35000 & no & ethanol \\
NC3 & 11.20 & 2.0 & 137000 & no & ethanol \\
NC4 & 12.00 & 2.3 & 312000 & no & ethanol \\
NC5 & 12.09 & 2.3 & 95000 & no & ethanol \\
NC6 & 12.20 & 2.3 & 29000 & no & ethanol \\
NC7 & 12.55 & 2.4 & 200000 & yes & water \\
NC8 & 13.42 & 2.8 & 69000 & yes & water \\
NC9 & 13.42 & 2.8 & 110000 & yes & water \\
\hline
\end{tabular}


Table 2: Nitrogen contents of NCs used in various formulated products obtained by the new method based on the molar ratio of nitrite to nitrate ions (this work), and as given by the manufacturer. Conditions for the alkaline hydrolysis: $1 \mathrm{M}$ sodium hydroxide for $1 \mathrm{~h}$ at $60^{\circ} \mathrm{C}$.

\begin{tabular}{cccc}
\hline Sample & \multicolumn{3}{c}{ Nitrogen content (\%) } \\
& \multicolumn{2}{c}{$\begin{array}{c}\text { This work } \\
\text { RSD (\%) }(\mathrm{n}=3)\end{array}$} & Manufacturer data \\
\hline Ping pong ball & $11.0 \pm 0.04$ & 0.4 & not available \\
NC membrane & $11.4 \pm 0.03$ & 0.2 & $<12.5$ \\
Nail polish & $11.8 \pm 0.01$ & 0.1 & $10.9-12.2$ \\
$\begin{array}{c}\text { Liquid bandage } \\
\text { Smokeless gunpowder } \\
\text { without graphite }\end{array}$ & $11.8 \pm 0.01$ & 0.1 & $11.7-12.2$ \\
$\begin{array}{c}\text { Smokeless gunpowder with } \\
\text { graphite }\end{array}$ & $13.2 \pm 0.09$ & 1.4 & $13.2 \pm 0.05$ \\
\hline
\end{tabular}

